\title{
UV-crosslinkable photoreactive self-adhesive hydrogels based on acrylics
}

\author{
Zbigniew Czech*, Adrian K. Antosik, Paulina Bednarczyk \\ West Pomeranian University of Technology, Szczecin, Pułaskiego 10, 70-322 Szczecin, Poland \\ "Corresponding author: e-mail: psa_czech@wp.pl
}

\begin{abstract}
Hydrogels are a unique class of macromolecular networks that can hold a large fraction of an aqueous solvent within their structure. They are suitable for biomedical area including controlled drug delivery and for technical applications as self-adhesive materials for bonding of wet surfaces. This paper describes photoreactive self-adhesive hydrogels based on acrylics crosslinked using UV radiation. They are prepared in ethyl acetate through radical polymerization of monomers mixture containing 2-ethylhexyl acrylate (2-EHA), butyl acrylate (BA), acrylic acid (AA) and copolymerizable photoinitiator 4-acryloyloxy benzophenone (ABP) at presence of radical starter 2.2'-azobis-diisobutyronitrile AIBN. The synthesized acrylic copolymers were determined by viscosity and GPC analysis and later modified using ethoxylated amines. 4-acryloyloxy benzophenone (ABP) was used as crosslinking monomer. After UV crosslinking the properties of these novel synthesized hydrogels, such as tack, peel adhesion, shears strength, elongation and water adsorption were also studied.
\end{abstract}

Keywords: self-adhesive hydrogels, acrylics, UV-crosslinking, tack, peel adhesion, water adsorption.

\section{INTRODUCTION}

Hydrogels are water swollen polymer matrices with a huge tendency to absorb water. Their ability to swell, under physiological conditions, makes them an ideal material for biomedical applications. The hydrophilicity of the network is due to the presence of chemical residues such as hydroxylic, carboxylic, amidic, sulphonic and others that can be found within the polymer backbone or as lateral chains. Hydrogels can be prepared from natural (chitosan, alginate, fibrin collagen, gelatin, hyaluronic acid, dextran) or synthetic polymers (2-hydroxy-ethylmethacrylate, 2-hydroxypropylmethacrylate, $\mathrm{N}$-vinyl-2-pyrrolidone), $\mathrm{N}$-isopropylacryl-amide, vinyl acetate, acrylic acid, methacrylic acid, polyethylene glycol acrylate and methacrylate, polyethylene glycol diacrylate and dimethacrylate $)^{8}$.

Hydrogels with self-adhesive properties are elastic polymeric films characterized by tack, adhesion, cohesion and water adsorption. In the polymeric network hydrophilic groups are present which are hydrated in an aqueous environment thereby creating the hydrogel structure. As the term "network" implies, crosslink have to be present to avoid dissolution of the hydrophilic polymer chain segments into the aqueous phase. It swells in water but does not dissolve. Hydrogels can be natural or synthetic provenance. The insolubility in water arises from the presence of crosslinks, covalent and physical nature, and entanglements. Because of their water-absorbing capacity, hydrogels are not only subject of investigation of researches interested in fundamental aspects of swollen polymeric networks, but have also found widespread application in different technological areas, such as wound dressing, technical tapes for bonding of wet substrates, contact lenses, matrices for cell-encapsulation and devices for the controlled release of drugs $1,2,9,10,11,13,14$.

Historically adhesives used in these applications have been pressure-sensitive adhesives based on natural rubber or synthetic acrylic-based chemistries ${ }^{2}$. Hydrogels based on acrylic polymers are of a widespread interest in technical and biomedical applications ${ }^{12}$. Photoreactive UV-crosslinkable hydrogels are compositions which cure to gels by exposure to UV radiation are made by blen- ding an unsaturated photoinitiator with copolymerizable double bonds. The crosslinking process of this kind of hydrogels can be adjusted by varying the concentration of unsaturated photoinitiators which is incorporated during polymerization into polymer chain ${ }^{1,5,6,7}$.

\section{EXPERIMENTAL}

Synthesis of self-adhesive acrylics for manufacturing of hydrogels

The synthesis of self-adhesive acrylic copolymers as precursor of hydrogels was performed by radical polymerization of monomers mixture containing 2-ethylhexyl acrylate (2-EHA), butyl acrylate (BA), acrylic acid (AA) and 4-acryloyloxy benzophenone (ABP) in ethyl acetate at $77^{\circ} \mathrm{C}$ using 0.1 wt.\% 2.2'-azo-bis-diisobutyronitrile (AIBN) as radical initiator by following polymerization conditions: $40 \mathrm{wt} . \%$ polymer content, $2 \mathrm{~h}$ dosage time of monomer mixture and $4 \mathrm{~h}$ post-reaction to reduce residue monomers. The compositions of synthesized self-adhesive acrylic copolymers were shown in Table 1. All monomers ethyl acetate and AIBN were purchased from POLY-CHEM (Germany) and unsaturated photoinitiator 4-acryloyloxy benzophenone (ABP) (Fig. 1) was synthesized at West Pomeranian University of Technology, Szczecin.

\section{Evaluation of viscosity and molecular weight}

The viscosity of the investigated solvent-borne methacrylic polymers was determined with a Rheomat RM 189 from Rheomatric Scientific, with spindle No 3 at $23^{\circ} \mathrm{C}$.

Table 1. Compositions of synthesized self-adhesive acrylic copolymers

\begin{tabular}{|l|c|c|c|c|}
\hline \multirow{2}{*}{ Copolymer-No } & \multicolumn{4}{|c|}{ Components [wt. \%] } \\
\cline { 2 - 5 } & 2-EHA & BA & AA & ABP \\
\hline 1 & 44.9 & 30 & 25 & 0.1 \\
\hline 2 & 44.8 & 30 & 25 & 0.2 \\
\hline 3 & 44.7 & 30 & 25 & 0.3 \\
\hline 4 & 44.5 & 30 & 25 & 0.5 \\
\hline 5 & 44.3 & 30 & 25 & 0.7 \\
\hline 6 & 44.0 & 30 & 25 & 1.0 \\
\hline 7 & 43.5 & 30 & 25 & 1.5 \\
\hline
\end{tabular}




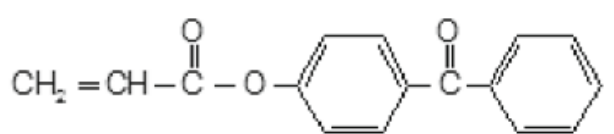

Figure 1. Thermogram of pure and contaminated 1-butyl-2-3-dimethyl imidazolium chloride (BDMIM-Cl)

The molecular weight studies were performed with a liquid chromatograph LaChrom system: RI Detector L-7490 and LaChrom UV Detector L-7400 from Merck Hitachi, equipped with a PLgel $10^{6} \AA$ column from Hewlet Pacard.

\section{Evaluation of residue monomers}

The amount of solid materials was found according to DIN EN 12092, the residual of monomers were measured with gas chromatograph Unicam 610, J\&W DB-1 column, FID detector and integrator Unicam 4815.

\section{Modification of synthesized acrylic copolymers}

The synthesized solvent-based acrylic copolymers were modified using ethoxylated diamine Ethoduomeen T/25 from Akzo Chemie (Fig. 2) in 100 wt.\%, 125 wt.\% and 150 wt.\% according to acrylic polymer amount. The reaction between carboxylic groups and ethoxylated diamine is illustrated in Figure 3.

\section{Preparation of polymer films}

For measurement of tack, peel adhesion and shear strength the modified copolymers containing various

$$
\begin{gathered}
\mathrm{R}-\mathrm{N}-\left(\mathrm{CH}_{2}\right)_{3}-\mathrm{N}-\left(\mathrm{C}_{2} \mathrm{H}_{4} \mathrm{O}\right)_{2} \mathrm{H} \\
1 \\
\left(\mathrm{C}_{2} \mathrm{H}_{4} \mathrm{O}\right)_{2} \mathrm{H}
\end{gathered}\left(\mathrm{C}_{2} \mathrm{H}_{4} \mathrm{O}\right)_{3} \mathrm{H}
$$

Figure 2. Chemical structure of ethoxylated amine Ethoduomeen $\mathrm{T} / 25$

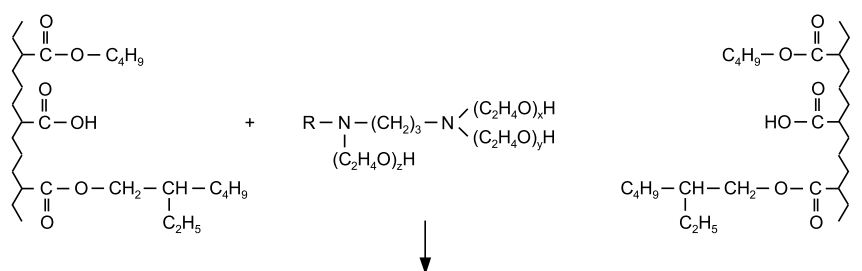

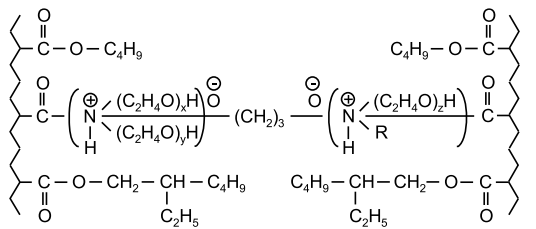

Figure 3. Reaction between carboxylic groups of polymer chain and ethoxylate diamine

concentrations of unsaturated photoinitiator $\mathrm{ABP}$ were coated with $120 \mathrm{~g} / \mathrm{m}^{2}$ coat weight on the corona-treated polyester film and dried in an oven $10 \mathrm{~min}$ at $110^{\circ} \mathrm{C}$. For evaluation of elongation and water adsorption in form of polymeric films the modified acrylic copolymers were coated with $120 \mathrm{~g} / \mathrm{m}^{2}$ coat weight on dehesive $75 \mathrm{~g} / \mathrm{m}^{2}$ silicon-paper and after that the adhesive layers were laminated eightfold with each other. It was received a $1000 \mathrm{~g} / \mathrm{m}^{2}$ thick hydrogel layers which before testing were storage 3 days at room temperature and about $65 \%$ relative humidity.

\section{UV-initiated crosslinking}

The obtained hydrogels films, $120 \mathrm{~g} / \mathrm{m}^{2}$ thick on polyester film and $1000 \mathrm{~g} / \mathrm{m}^{2}$ thick on silicon paper, were UV-crosslinked by $150 \mathrm{~mJ} / \mathrm{cm}^{2} \mathrm{UV}$ dose under UV-lamp UVASPOT $400 \mathrm{~T}$ with self constructed transmission belt.

The UV-exposure can be measured using an integrating radiometer Dynachem ${ }^{\mathrm{TM}}$ Model 500, available from Dynachem Corporation, 2631 Michelle Drive, Tustin, CA 92680.

\section{Measurement of tack, peel adhesion, shear strength and elongation}

The influence of the UV-initiated crosslinking on self-adhesive properties, such as tack, peel adhesion and shear strength was determinate by standard A.F.E.R.A. (Association des Fabricants Europeens de Rubans Auto-Adhesifs) procedures, administrative address: 60, rue Auber-94408 Vitry Sur Seine Cedex, France. Exact details can be found in AFERA 4015 (tack), AFERA 4001 (peel adhesion) and AFERA 4012 (shear strength). The increase in a sample's gauge length measured after a rupture divided by the sample's original gauge length is referred to as elongation.

\section{Adsorption of water (swelling properties)}

When a hydrogel in its initial state is placed in an aqueous solution, water molecules will penetrate into the polymer network. Hydrogels layers were swollen in deionized water at room temperature during the time of $4 \mathrm{~h}$. After $72 \mathrm{~h}$ of incubation to assure reaching equilibrium, hydrogel samples were carefully taken out from the solution, blotted with a filter paper to remove free water from the surface, and then weighed $\left(\mathrm{W}_{\text {wet }}\right)$. It was then freeze-dried for $1 \mathrm{~h}$ and weighed again $\left(\mathrm{W}_{\mathrm{dry}}\right)$. The swelling ratio $Q$ (adsorption of water) was evaluated using the equation:

$Q=\frac{W_{1}-W_{0}}{W_{0}}$

where, $\mathrm{W}_{1}$ and $\mathrm{W}_{0}$ refer to the weight $[\mathrm{g}]$ of the hydrogel in swollen and dried state, respectively.

\section{RESULTS AND DISCUSSION}

\section{Viscosity and molecular weight of synthesizes acrylic copolymers}

The synthesized acrylic copolymers were characterized by viscosity, weight average molecular weight $\left(\overline{\mathrm{M}}_{\mathrm{w}}\right)$, number average molecular weight $\left(\overline{\mathrm{M}}_{\mathrm{n}}\right)$, and polydispersity $\left(\mathrm{P}_{\mathrm{d}}\right)$. The mentioned properties were presented in Table 2.

As shown in Table 2 the concentration increasing of the unsaturated photoinitiator $\mathrm{ABP}$ incorporated into polymer chain increase clear both molecular weights and the viscosity of synthesized photoreactive acrylic copolymers. The influence of ABP concentration on viscosity and weight average molecular weight $\left(\bar{M}_{w}\right)$ of synthesized acrylic copolymers is illustrated in Figs. 4-5. 
Table 2. Viscosity and molecular weight of synthesized acrylic copolymers

\begin{tabular}{|l|c|c|c|c|}
\hline $\begin{array}{l}\text { ABP concentration } \\
\text { [wt.\%] }\end{array}$ & $\begin{array}{c}\text { Viscosity } \\
{[\mathrm{Pa} \cdot \mathrm{s}]}\end{array}$ & $\begin{array}{c}\overline{\mathrm{M}}_{\mathrm{w}} \\
\text { [Dalton] }\end{array}$ & $\begin{array}{c}\overline{\mathrm{M}}_{\mathrm{n}} \\
\text { [Dalton] }\end{array}$ & $\mathrm{P}_{\mathrm{d}}=\frac{\overline{\mathrm{M}}_{\mathrm{w}}}{\overline{\mathrm{M}}_{\mathrm{n}}}$ \\
\hline 0.1 & 6.3 & 438000 & 103000 & 4.3 \\
\hline 0.2 & 6.6 & 450000 & 108000 & 4.2 \\
\hline 0.3 & 7.6 & 464000 & 117000 & 4.0 \\
\hline 0.5 & 9.0 & 514000 & 133000 & 3.9 \\
\hline 0.7 & 10.4 & 591000 & 161000 & 3.7 \\
\hline 1.0 & 16.7 & 696000 & 199000 & 3.5 \\
\hline 1.5 & 38.5 & 917000 & 291000 & 3.2 \\
\hline
\end{tabular}

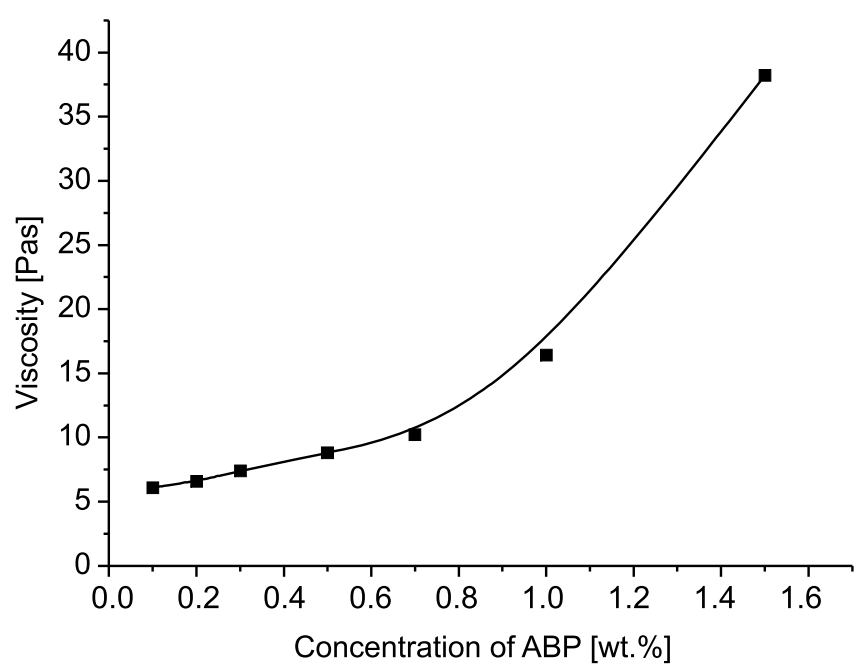

Figure 4. Viscosity of synthesized acrylic copolymers as a function of $\mathrm{ABP}$ concentration

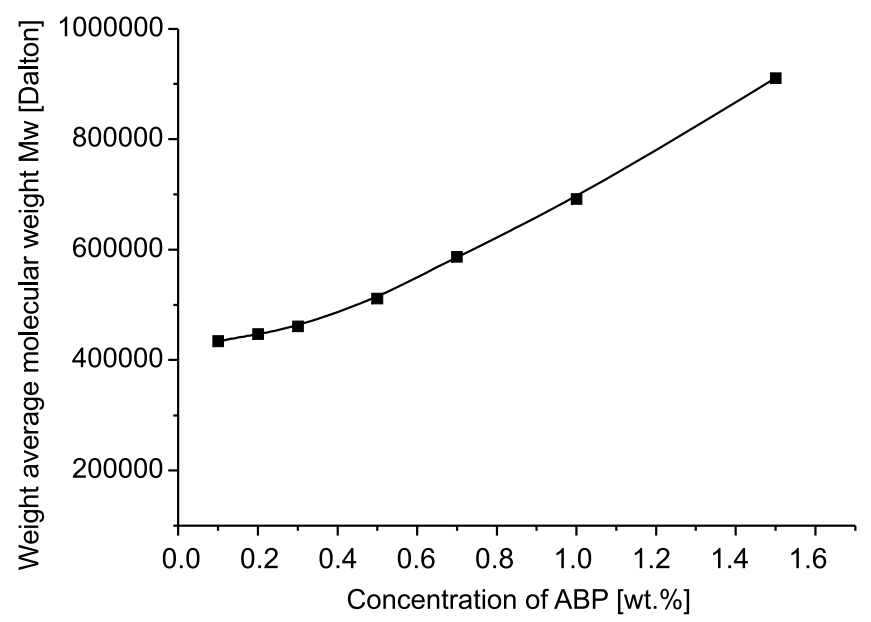

Figure 5. Molecular weight MW of synthesized acrylic copolymers as a function of ABP concentration

\section{Residue monomers}

The concentration of residue monomers was on very low level under $0.1 \mathrm{wt} . \%$ what predestinate this kind of copolymers for manufacturing of medical and technical hydrogel materials.

Tack, peel adhesion, shear strength and elongation of prepared hydrogels

Typical performance characteristics for crosslinked self-adhesive hydrogels before water adsorption, such as tack, peel adhesion, shear strength (at $20^{\circ} \mathrm{C}$ and $70^{\circ} \mathrm{C}$ ) and elongation as a function of the unsaturated photoinitiator ABP and ethoxylated diamin Ethoduomeen T/25 concentration were presented in Figs. 6-9.
The tack behavior strongly depends upon the crosslinking ratio and also the 4-acryloyloxy benzophenone (ABP) content. Studies have shown that the crosslinking stage for the tack level is also an important parameter. By increasing the unsaturated photoinitiator ABP concentration, the tack of acrylic hydrogel decreases rapidly (Fig. 6).

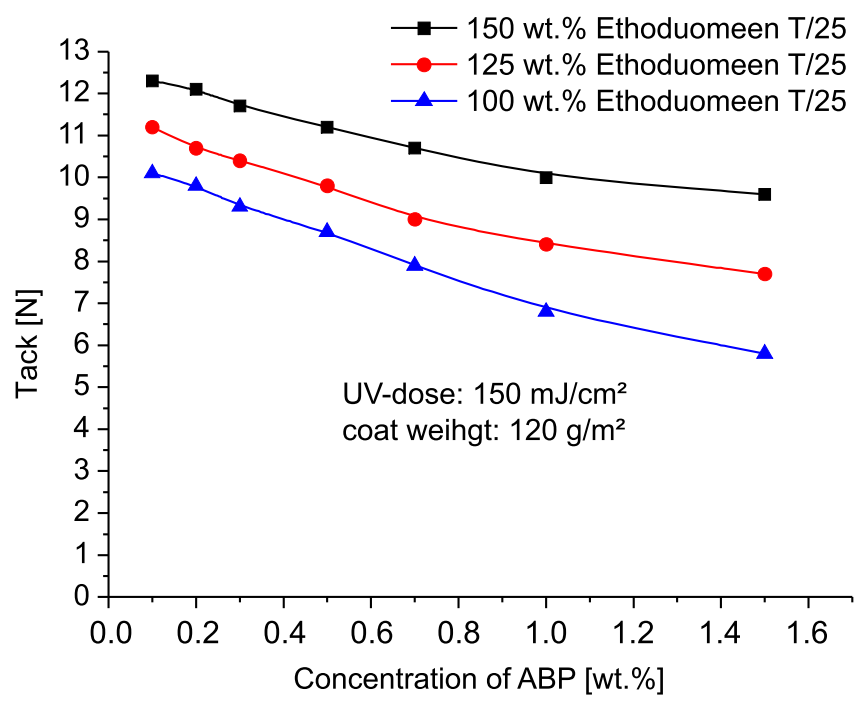

Figure 6. Tack of self-adhesive hydrogels according AFERA 4015 as a function of ABP concentration

The effective photoinitiator concentration during the UV initiated crosslinking of self-adhesive acrylic hydrogels is recorded for the purpose of peel adhesion amendment. The maxima of peel adhesion values were observed for 100 wt.\% Ethoduomeen T/25 by 0.3 wt.\% ABP, for 125 wt. $\%$ Ethoduomeen $\mathrm{T} / 25$ by $0.5 \mathrm{wt} . \% \mathrm{ABP}$ and for 150 wt.\% Ethoduomeen T/25 by 0.7 wt. $\%$ ABP. Obviously, the increasing of photoinitiator concentration above $0.7 \mathrm{wt} . \%$ exerts a decisive effect on the peel adhesion decrease of UV-crosslinked hydrogels (Fig. 7).



Figure 7. Peel adhesion of self-adhesive hydrogels according AFERA 4001 as a function of ABP concentration

Incorporation of unsaturated photoinitiators ABP into acrylic polymer structure influences strongly the shear strength properties of the UV-crosslinked self-adhesive hydrogels (Fig. 8). An increase of the concentration of investigated photoinitiators produces, after UV exposure a higher network density, leading to higher cohesion in comparison with classical conventional photoinitiator 


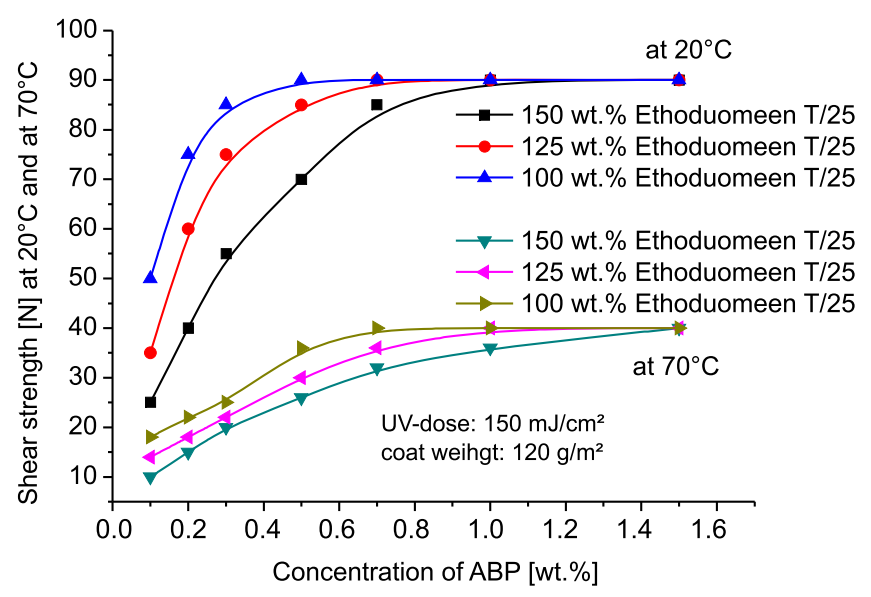

Figure 8. Shear strength levels of self-adhesive hydrogels according AFERA 4012 at $20^{\circ} \mathrm{C}$ and $70^{\circ} \mathrm{C}$ as a function of ABP concentration

systems. The highest shear strength results were observed for about $0.7 \mathrm{wt} . \% \mathrm{ABP}$ using $100 \mathrm{wt} . \%$ Ethomeen T/25.

Figure 9 illustrates the elongation of UV-crosslinked hydrogels films with coating weight $1000 \mathrm{~g} / \mathrm{m}^{2}$ as a function of 4-acrylyloxy benzophenone (ABP) concentration.

It was observed that the increasing of $\mathrm{ABP}$ concentration and decreasing of modified ethoxylated amine Ethoduomeen $\mathrm{T} / 25$ have a negatively influence on elongation of acrylic hydrogel layers. The increase of ABP content from 0.1 wt. $\%$ to 1.5 wt. $\%$ reduces the elongation of hydrogel layers from $285 \%$ to $160 \%$ for 150 wt.\% Ethoduomeen T/25 and from $210 \%$ to $80 \%$ for $100 \mathrm{wt} . \%$ Ethoduomeen $\mathrm{T} / 25$.

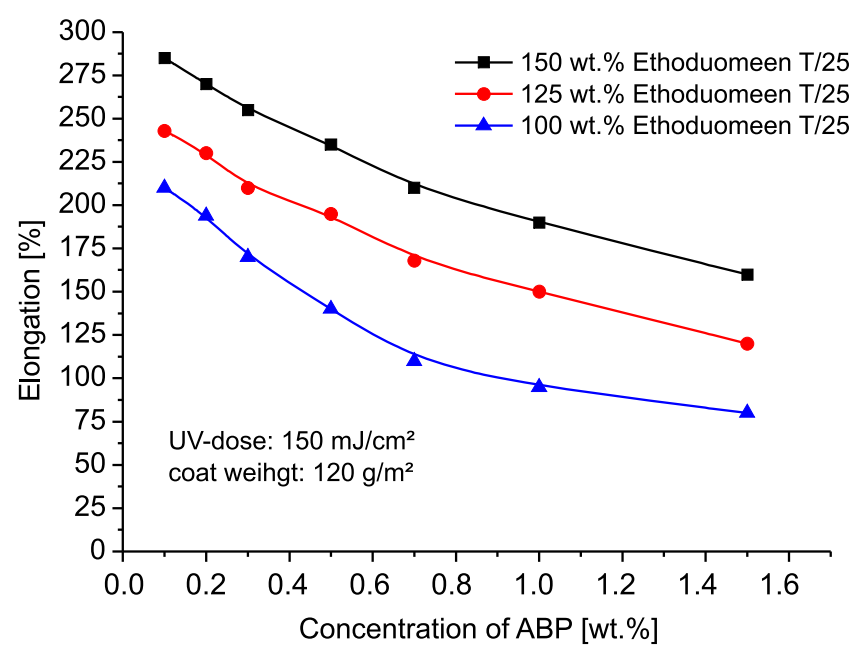

Figure 9. Elongation of self-adhesive hydrogels as a function of $\mathrm{ABP}$ concentration

\section{Adsorption of water (swelling properties)}

The results of swelling experiments demonstrate that the concentration of unsaturated photoinitiator ABP incorporated during polymerization into polymer chain significantly affects the subsequent equilibrium swelling of hydrogel films. The water adsorption was measured for hydrogels containing $0.7 \mathrm{wt} . \%$ ABP for $100 \mathrm{wt} . \%$ Ethoduomeen $\mathrm{T} / 25$ and $0.3 \mathrm{wt} . \%$ ABP for $150 \mathrm{wt} . \%$ Ethoduomeen T/25. The UV-crosslinked hydrogel films containing 0.1 and $0.2 \mathrm{wt} . \% \mathrm{ABP}$ were after water adsorption not mechanically stable.

The representative curve of hydrogel layer swelling as a function of time is measure how extended the backbone polymer chain are in solution and varies with solvent quality and the degree of polymer chains solvation. The entering molecules are going to occupy some space, and as a result some meshes of the network will start expanding, allowing other water molecules to enter within the network. Because the swelling process is specific to the polymer composition and it is extremely various dependence on crosslinking kind and concentration. With increasing of ABP concentration increases the crosslinking density of self-adhesive acrylic hydrogels and it results in lower swelling ratio (Fig. 10). The dramatic increasing in the amount of swelling is observed with the decrease of the amount of ABP. For 1.5 wt.\% ABP the lowest water adsorption but the best mechanical properties of hydrogel layer was observed.

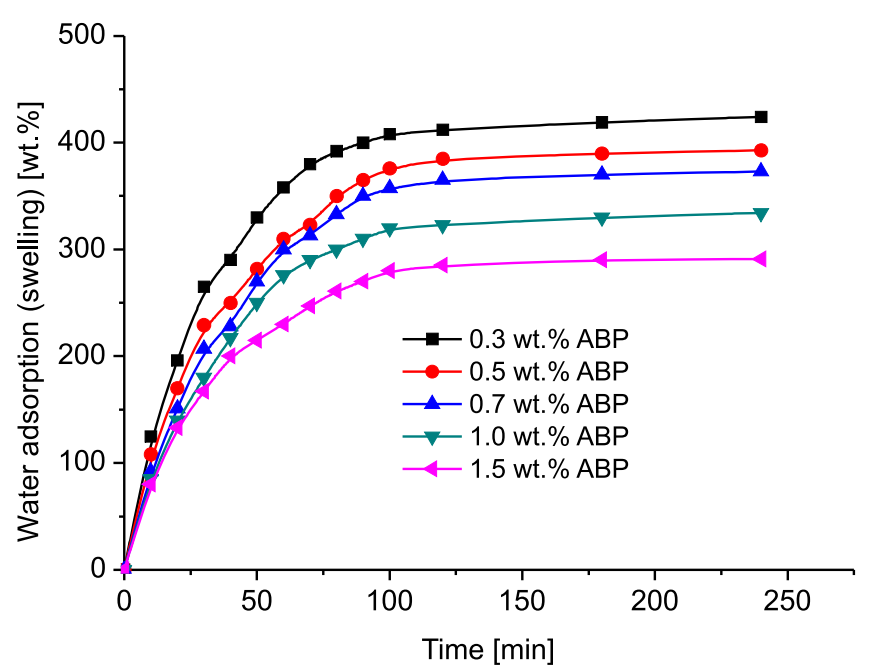

Figure 10. Swelling grade of self-adhesive acrylic hydrogel as a function of time

\section{CONCLUSIONS}

During past decades, hydrogels have played a very essential role in biomedical and technical applications. New synthetic and crosslinking methods have been used to prepare polymeric hydrogels. Recent enhancements in the field of polymer science and technology have led to the development of various stimuli sensitive hydrogels. Recent advances in the development of novel hydrogels films characterized by pressure-sensitive properties have focused on several aspects of their synthesis, characterization and behavior. Novel hydrogel systems have been developed, tailored, manufactured and applied in a wide range of industry branches, such as: technical tapes, medical and pharmaceutical fields. In the giant field of hydrogels the self-adhesive hydrogels make up but a low percentage and they are almost a quantity negligible within this group. The developed and describes in this study self-adhesive hydrogels based on acrylics were synthesized by radical polymerization of selected acrylic monomers in ethyl acetate and UV-crosslinked using unsaturated copolymerizable photoinitiator 4-acryloyloxy benzophenone (ABP). The resulted hydrogels manufactured through modification of acrylic pressure-sensitive adhesives using ethoxylated amine are characterized by low tack and low peel adhesion, very important factors by removability from skin (tested with hand on own skin), excellent shear strength at room temperature and at higher temperatures $\left(70^{\circ} \mathrm{C}\right)$, very high elongation 
in form of polymeric films and very interesting run of water adsorption, other knows as swelling rate. After adsorption of water the hydrogel films are characterized through good mechanical stability. They can be applied in technical area for bonding of wet substrates and in medical area as wound-dressing materials.

\section{LITERATURE CITED}

1. Alvarez-Lorenzo, C. \& Concheiro, A. (2002). Reversible adsorption by a $\mathrm{pH}$ - and temperature-sensitive acrylic hydrogel. J. Cont. Rel. 80, 247-257. DOI: 10.1016/S0168-3659(02)00032-9.

2. Bajpai, S.K. (1999). Hydrogels for Colon-specific Oral Drug Delivery: An In Vitro Drug Release Study (II). Iran Polym. J. 8, 231-239.

3. Chen, J., Bevins, W.E., Park H. \& Park H. (200). Gastric retention properties of superporous hydrogel composites. J. Con. Rel. 64, 39-51. DOI: 10.1016/S0168-3659(99)00139-X.

4. Czech, Z., Butwin, A., Kabatc, J. \& Świderska, J. (2012). UV-crosslinkable acrylic pressure-sensitive adhesives for industrial application. Polym. Bull. 69, 71-80. DOI: 10.1007/ s00289-012-0725-y.

5. Czech, Z., Butwin, A., Kabatc, J., Świderska, J., Shao, L. \& Bai, Y. (2012). Influence of selected photoinitiators type II on tack, peel adhesion, and shear strength of UV-crosslinked solvent-borne acrylic pressure-sensitive. Polym. Bull. 68, 441-452. DOI: 10.1007/s00289-011-0563-3.

6. Czech, Z., Kowalczyk, A., Kabatc, J. \& Świderska, J. (2012). Photoreactive UV-crosslinkable solvent-free acrylic pressuresensitive adhesives containing copolymerizable photoinitiators based on benzophenones. Eur. Polym. J. 48, 1446-1454. DOI: 10.1016/j.eurpolymj.2012.05.010.

7. Czech, Z., Kowalczyk, A., Kabatc, J., Shao, L., Bai, Y. \& Świderska, J. (2013). UV-initiated crosslinking of photoreactive acrylic pressure-sensitive adhesives using excimer-laser. Polym. Bull. 70, 479-488. DOI: 10.1007/s00289-012-0818-7.

8. Ganji, F. \& Vasheghani-Farahani, E. (2009). Hydrogels in Controled Drug Delivery Systems. Iran Polym. J. 18, 63-88.

9. Hiemstra, C., Zhong, Z. \& Feijen, J. (2007). Patent WO 2008/113390.

10. Langer, R.S. \& Peppas, N.A. (1981). Present and future application of biomaterials controlled drug delivery system. Biomaterials. 2, 201-214. DOI: 10.1016/0142-9612(81)90059-4.

11. Pietsch, H. \& Borgschulte, K. (1089). Patent DE 3928858.

12. Podkościelna, B., Bartnicki, A. \& Gawdzik, B. (2012). New crosslinked hydrogels derivatives of 2-hydroxyethyl methacrylate: Synthesis, modifications and properties. eXPRESS Polym. Lett. 9, 759-771.

13. Wang, J.Q. \& Satoh, M. (2010). A novel reversible thermo-swelling hydrogel. eXPRESS Polym. Lett. 7, 450-454. DOI: 10.3144/expresspolymlett.2012.81.

14. Zohuriaan-Mehr, M.J. \& Kabiri, K. (2008). Superabsorbent Polymer Materials: A Review. Iran Polym. J. 17, 451-477. DOI: 10.3144/expresspolymlett.2010.56. 